
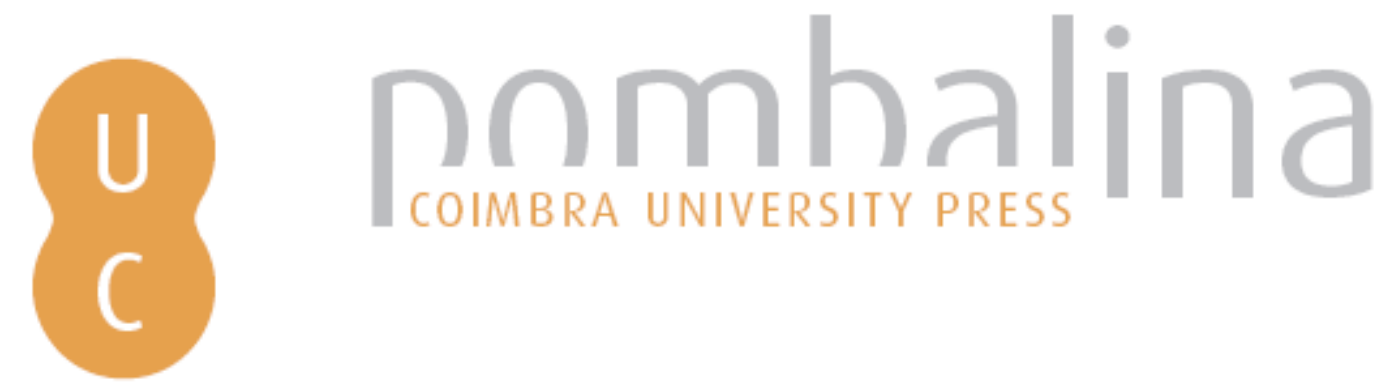

\title{
A Biblioteca, coração de uma Faculdade: o caso da Faculdade de Letras da Universidade de Lisboa
}

\author{
Autor(es): $\quad$ Serra, José Pedro \\ Publicado por: Imprensa da Universidade de Coimbra \\ URL \\ persistente: URI:http://hdl.handle.net/10316.2/36978 \\ DOI: $\quad$ DOI:http://dx.doi.org/10.14195/978-989-26-1045-0_7 \\ Accessed : $\quad$ 26-Apr-2023 11:04:32
}

A navegação consulta e descarregamento dos títulos inseridos nas Bibliotecas Digitais UC Digitalis, UC Pombalina e UC Impactum, pressupõem a aceitação plena e sem reservas dos Termos e Condições de Uso destas Bibliotecas Digitais, disponíveis em https://digitalis.uc.pt/pt-pt/termos.

Conforme exposto nos referidos Termos e Condições de Uso, o descarregamento de títulos de acesso restrito requer uma licença válida de autorização devendo o utilizador aceder ao(s) documento(s) a partir de um endereço de IP da instituição detentora da supramencionada licença.

Ao utilizador é apenas permitido o descarregamento para uso pessoal, pelo que o emprego do(s) título(s) descarregado(s) para outro fim, designadamente comercial, carece de autorização do respetivo autor ou editor da obra.

Na medida em que todas as obras da UC Digitalis se encontram protegidas pelo Código do Direito de Autor e Direitos Conexos e demais legislação aplicável, toda a cópia, parcial ou total, deste documento, nos casos em que é legalmente admitida, deverá conter ou fazer-se acompanhar por este aviso.

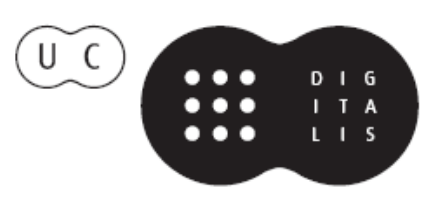



Tendo como pano de fundo as Comemorações dos seus 500 anos, a Biblioteca Geral da Universidade de Coimbra organizou um Congresso Internacional subordinado ao tema "A Biblioteca da Universidade: permanência e metamorfoses", que teve lugar nos dias 16, 17 e 18 de janeiro de 2014, no auditório da Reitoria da Universidade de Coimbra.

O objetivo maior desta reunião científica foi o de refletir sobre o presente e o futuro das bibliotecas que servem públicos universitários. Numa outra vertente, procurou chamar-se a atenção para a importância de que a Biblioteca se reveste, tendo em vista o progresso do conhecimento técnico e científico. Por último, o Congresso pretendeu instituir-se como oportunidade de reflexão prospetiva e como lugar de encontro entre as sensibilidades de todos os que trabalham profissionalmente com livros e com outros suportes de natureza bibliográfica.

Nesse sentido, foram apresentadas Conferências, Mesas Redondas e sessões de Testemunhos em torno de temas como o valor das bibliotecas universitárias, a biblioteca universitária em contexto; as mudanças e os desafios; a biblioteca universitária e a sociedade da informação e conhecimento; o impacto do acesso aberto na comunidade científica, e as bibliotecas digitais. 


\section{JOSÉ PEDRO SERRA}

Universidade de Lisboa

University of Lisbon

A BIBLIOTECA, CORAÇÃO DE UMA FACULDADE:

O CASO DA FACULDADE DE LETRAS

DA UNIVERSIDADE DE LISBOA

THE LIBRARY AT THE HEART OF THE FACULTY:

THE CASE OF THE UNIVERSITY OF LISBON

FACULTY OF LETTERS

RESUMO: A minha comunicação incidirá sobre a lugar da Biblioteca na Faculdade de Letras da Universidade de Lisboa, bem como sobre as decisões políticas e estratégicas que a direcção da Biblioteca, em consonância com a direcção da Faculdade, vem adoptando. Tratar-se-á, igualmente, dos principais projectos em curso e das dificuldades que a sua realização levanta.

ABSTRACT: This paper explores the role of the Faculty of Letters library at the University of Lisbon and the political and strategic decisions adopted by the library management, together with the Faculty directors. It also addresses the main ongoing projects and the difficulties which emerged during the course of their implementation.

A minha colaboração neste colóquio, que, celebrando muito oportunamente os quinhentos anos da Biblioteca Geral da Universidade de Coimbra, promove uma reflexão conjunta sobre o lugar e a função da biblioteca no contexto universitário, baseia-se, fundamentalmente, na minha experiência dos últimos anos como Director da Biblioteca da Faculdade de Letras da Universidade de Lisboa. Ao longo deste tempo, tive oportunidade de acompanhar a transformação por que passou esta biblioteca e que, inevitavelmente, para além de condicionalismos próprios, se insere nas grandes transformações por que passam em geral as bibliotecas. 
Julgo que uma das mais importantes alterações ocorridas relaciona-se com uma mudança no modo como é encarado o utente da biblioteca e como são percebidas as suas necessidades e pretensões. Em tempos não muito distantes, a política de utilização dos recursos das bibliotecas manifestava, sobretudo, um desmedido desejo de guarda e de reserva, que em muito dificultava o ritmo de consulta e de investigação por parte dos leitores. Não está em causa, evidentemente, o zelo que as bibliotecas devem ter na defesa, na segurança e na conservação dos seus espólios; o que acontece, porém, é que a defesa do património não é o único objectivo de uma biblioteca e é necessário encontrar um equilíbrio entre guarda e divulgação, entre preservação e disponibilização dos acervos. Aceitando o estatuto de fiel depositária do património que vai acolhendo, a biblioteca, genericamente, ganhou consciência de que, tão importante quanto esse zelo, é também o dever de dar a conhecer esse património. No caso das bibliotecas universitárias, é sua missão primordial proporcionar as melhores condições possíveis de investigação e ensino a toda a comunidade académica, nomeadamente a estudantes, professores e investigadores. Este aspecto é hoje, mais do que nunca, central e decisivo para as Universidades. Depois do acordo de Bolonha, e com o intercâmbio de estudantes existente na Europa, ao abrigo, por exemplo, do programa Erasmus, a concorrência entre as Universidades baseia-se não apenas na competência da leccionação, mas também nas condições oferecidas para a aprendizagem e a investigação, de que a biblioteca é um aspecto muitíssimo relevante. A inexistência de uma biblioteca que forneça os elementos necessários para a investigação dos segundos e terceiros ciclos fere de morte uma Universidade, desvalorizando-a, marginalizando-a, remetendo-a para uma espécie de segundo plano do roteiro internacional das Universidades. Compreende-se, assim, o longínquo alcance das questões relacionadas com as bibliotecas universitárias.

A par desta metamorfose, coloca-se ainda às bibliotecas o desafio das novas tecnologias de informação e dos recursos digitais, de entre os quais destacaria quer as importantíssimas bases de dados, hoje condição relevante para o acesso às publicações, quer a digitalização de obras antigas de consulta reservada, não apenas por razão de facilidade de consulta, mas 
também por razões de conservação. Se não é possível negligenciarmos estes novos instrumentos de estudo e de investigação, tal não significa que se desvalorize o enriquecimento dos tradicionais acervos em papel.

Partindo destes sucintos pressupostos, vejamos agora o caso concreto da Biblioteca da FLUL, qual a sua política científica, como se organiza e como serve a comunidade académica - objectivo primeiro - e o público em geral $^{1}$.

\section{O Edifício da Biblioteca}

O novo edifício da Biblioteca da Faculdade de Letras, cuja construção terminou no ano 2000, implicou profundas mudanças na concepção e no funcionamento da Biblioteca da Faculdade de Letras. A mais decisiva alteração, sobretudo tendo em conta que a Universidade de Lisboa não dispõe de uma biblioteca geral, consistiu na transferência das chamadas bibliotecas departamentais, que passaram a integrar a Biblioteca da Faculdade, anteriormente designada por Biblioteca Central. Tal integração permitiu uma gestão muito mais eficaz dos recursos humanos e das aquisições, quer do ponto de vista geral (isto é, de interesses comuns e de temática genérica), quer do ponto de vista do interesse das especialidades departamentais. Houve, na altura, um alargado debate interno acerca da pertinência do crescimento da biblioteca geral e da decorrente questão da transferência dos espólios dos vários departamentos e institutos. Alegavam alguns que o afastamento físico dos livros - ainda que o edifício da Biblioteca tivesse, como tem, ligação directa ao corpo central da FLUL - prejudicaria o estudo e a investigação daqueles que frequentavam os vários departamentos. A experiência mostrou exactamente o contrário. A integração das diversas bibliotecas dispersas pela Faculdade na nova

\footnotetext{
1 Refiro este aspecto porque a Biblioteca da FLUL tem assistido a um aumento considerável de leitores externos. Embora tal facto seja significativo e louvável, e não haja qualquer intenção de fechar a Biblioteca ao público externo, é preciso não esquecer que, enquanto Biblioteca da Faculdade de Letras, esta biblioteca se dirige antes de mais à comunidade académica.
} 
Biblioteca permitiu uma melhoria substantiva na disponibilização e na gestão dos diversos espólios, bem como na prossecução de uma política científica muito mais eficaz. Núcleos bibliográficos que eram de difícil consulta, ora porque os acervos não estavam devidamente tratados e informatizados - e não era fácil os departamentos encontrarem meios para o fazerem - e consequentemente permaneciam mais ou menos desconhecidos, ora porque os recursos humanos eram escassos e daí decorria que o horário de atendimento era muito reduzido, poderiam, a partir de então, desde que se delineasse uma adequada política científica, ficar à disposição dos investigadores e dos estudantes.

\section{Reforma Estatutária}

Antes de abordarmos a política científica, é oportuno referir que a alteração estatutária que ocorreu nas Universidades portuguesas em 2008 desencadeou modificações significativas na estrutura da Biblioteca. Antes, existia um Conselho de Biblioteca, coordenado pelo Presidente, do qual faziam parte o Chefe de Divisão da Biblioteca e os representantes dos vários Departamentos, e que decidia colegialmente a política científica, nomeadamente, a importante questão das compras. Esta estrutura, um pouco pesada, nem sempre possuía a agilidade necessária para a resolução rápida e oportuna das diversas questões que se iam colocando ${ }^{2}$. Os novos estatutos, mantendo a Divisão da Biblioteca e o Chefe de Divisão, e reconhecendo a importância e a especificidade da Biblioteca, criaram a figura do Director, um professor doutorado, a quem se atribui a responsabilidade da efectivação da política científica, e que depende directamente do Director da Faculdade e do Conselho Científico. O Conselho

2 É justo referir aqui o nome da Professora Doutora Helena Buescu, presidente do último Conselho de Biblioteca, que, em condições nem sempre favoráveis, não só teve um papel decisivo na afirmação da importância do papel desempenhado pela Biblioteca no contexto da Faculdade, como também lançou as bases de uma diferente política científica. 
de Biblioteca, integrando um representante por área científica ${ }^{3}$, além do Chefe de Divisão, que desempenha papel central na organização e gestão dos funcionários da Biblioteca ${ }^{4}$, passou a ser um órgão consultivo, ainda que da maior importância. Tal reforma teve a vantagem de clarificar os traços fundamentais da política científica e da organização da Biblioteca, responsabilizando o seu Director pelas decisões tomadas e dando-lhe os instrumentos para a prossecução das suas decisões.

\section{Política Científica e Cultural}

A concretização de qualquer política científica de uma biblioteca universitária, ainda que muito bem esboçada, depende sempre do apoio convincente da entidade superior, seja ela o director da Faculdade ou o reitor. Sem isso, o projecto não passará de boas intenções. No caso da FLUL, e depois das alterações estatutárias decorrentes das imposições legais de 2008, os directores, compreendendo a importância vital da Biblioteca para a estratégia global da Faculdade de Letras, não têm faltado com o seu imprescindível apoio, inclusivamente do ponto de vista financeiro ${ }^{5}$.

Desde então, a política científica da Biblioteca tem-se desenvolvido a partir de três perspectivas fundamentais: preservação e enriquecimento do património bibliográfico e arquivístico, com a inevitável abertura aos novos meios tecnológicos; melhoria do funcionamento e da prestação de serviços; difusão cultural, procurando projectar a Biblioteca para além dos muros da Faculdade. Vejamos globalmente estes aspectos.

3 Nos novos estatutos, os vários Departamentos foram agrupados em áreas científicas, no caso, Filosofia, História, Ciências da Linguagem e LAC (Literaturas, Artes e Culturas). São estas áreas que têm representação no Conselho de Biblioteca.

${ }^{4}$ Por justiça, não posso deixar de citar o nome do Dr. Pedro Estácio, Chefe de Divisão da Biblioteca à altura da alteração dos estatutos - e que se mantém no cargo -, com quem tenho trabalhado muito proximamente, em total coordenação.

5 Não posso deixar de salientar a política seguida pelo Professor António Feijó, Director da FLUL entre 2008 e 2013, que, colocando a Biblioteca entre as mais urgentes prioridades da Faculdade, lhe concedeu condições de que nunca antes tinha disposto. O actual Director, Professor Paulo Alberto, tem procurado seguir a mesma orientação política, continuando a dedicar à Biblioteca uma cuidadosa atenção. 
Tendo em conta as circunstâncias existentes em 2009, duas situações impunham uma resolução urgente $^{6}$ : a informatização do tratamento das obras e o tratamento de doações e outros espólios que há muito estavam acumulados em depósito. A questão do tratamento informático das obras, nomeadamente a sua inclusão no Sistema Integrado das Bibliotecas da Universidade de Lisboa (SIBUL), era uma prioridade óbvia. Um leitor que então se dirigisse à Biblioteca, e saliente-se que se trata de uma biblioteca de consulta directa, deveria consultar o catálogo das obras que estava já informatizado $^{7}$ e consultar igualmente o ficheiro manual - pode-se imaginar os inconvenientes e a perda de tempo que tal procedimento implicava. Era, pois, urgente informatizar estes catálogos e a este objectivo foi dada uma importância relevante. A partir de 2009, com especial relevo para o período compreendido entre 2011 e 2013, a Biblioteca empenhou-se no tratamento informático das obras que estavam em consulta directa, particularmente aqueles espólios que vinham transferidos das bibliotecas departamentais, de modo a que, nas suas investigações, os leitores pudessem evitar os malefícios da dispersão pelos diversos ficheiros manuais ${ }^{8}$. Satisfeita esta condição básica, outras questões se impunham com análoga premência: a questão das doações e o tratamento do livro antigo. A questão das doações constituía - e ainda constitui - uma delicada questão. Considero indecoroso que uma instituição aceite a doação de espólios, alguns deles de enorme valor, sem que lhes dê o tratamento documental devido, pondo-os à disposição da comunidade dos leitores, e, ao contrário disto, consinta que permaneçam nas sombras dos depósitos, atravessando

6 A isto, deve ainda juntar-se a questão do arquivo histórico, situação que, infelizmente, ainda não pôde ser resolvida, mas cuja resolução está já pensada.

7 Desde 1986, creio, que os serviços da Biblioteca (então chamada Biblioteca Central) faziam o tratamento informático das obras compradas, ao mesmo tempo que faziam alguma conversão retrospectiva, isto é, o tratamento informático de obras anteriormente adquiridas. De igual modo, alguns Departamentos e alguns Institutos, que estavam integrados nas bibliotecas departamentais, trataram igualmente os seus espólios, como foi o caso de Linguística e de Anglísticos.

8 Entre 2011 e 2013, além do tratamento das obras anualmente adquiridas, a Biblioteca, nesta conversão retrospectiva, tratou mais de 14.000 volumes pertencentes, por exemplo, ao Instituto Clássico André de Resende, ao Instituto de Cultura Alemã, ao Instituto de Cultura Brasileira, ao Instituto de Cultura Neerlandesa, Instituto Fernão Lopes, Instituto Infante D. Henrique. 
os tempos em distinta fama ignorada. Quando uma instituição aceita doações - e é necessário estabelecer critérios para essa aceitação - tem a obrigação, por respeito e interesse, de tratar e de divulgar esses espólios em tempo razoável. Por esta razão, outra das prioridades estabelecidas foi o tratamento dos diversos acervos, alguns há tempo doados (outros adquiridos em circunstâncias vantajosas) e que permaneciam encerrados nos depósitos. O critério adoptado foi pragmático: todas as doações que fossem feitas a partir desse momento eram imediatamente tratadas (num espaço razoável de um ano ou ano e meio); relativamente às anteriores, iniciava-se um processo de conversão retrospectiva que visava terminar com o "adormecimento" dos acervos no depósito. Simultaneamente, estabeleceu-se um critério mais rigoroso para a aceitação de doações uma vez que, sem pôr em causa a generosa intenção dos doadores, a Biblioteca não dispõe nem de espaço, nem de meios humanos que lhe permitam aceitar doações que não apresentem manifesto interesse para ela. Estes cuidados e estas restrições, ao contrário de diminuir o número de doações, foram acompanhados pelo aumento do número de espólios doados, porventura porque os próprios beneméritos puderam verificar o empenhamento na cuidadosa disponibilização desses espólios ${ }^{9}$. E ainda que a conversão retrospectiva não tenha terminado, alguns dos acervos foram já tratados ${ }^{10}$ e impediu-se que o número de obras em depósito, inúteis porque não tratadas, aumentasse. O alargamento para a aceitação de espólios de arquivo, pelo que pode representar de matéria-prima para variadas investigações, nomeadamente para teses de mestrado e doutoramento, é também uma área relativamente à qual a Biblioteca começou a

9 De 2011 a 2014, a Biblioteca da FLUL teve a honra de receber os seguintes espólios: Maria Carlota Rodrigues de Almeida/António Rodrigues de Almeida, Margarida Vieira Mendes, Isabel Castro Henriques/Alfredo Margarido, Manuel S. Lourenço, Carlos Adrião Rodrigues, Eduardo Chitas, Michel Labin, Luiz Francisco Rebello, Francisco Vieira de Almeida, Júlio Carlos Viana Ferreira, Teresa Amado, Manuel Díaz y Díaz, Jacinto do Prado Coelho, Manuel Ferreira, Rui Mário Gonçalves, José Azevedo. A estas doações particulares deve ainda juntar-se as doações institucionais da Fundação Calouste Gulbenkian, da Embaixada da Índia e da Associação Iúri Gagárin.

10 Refiro-me, por exemplo aos acervos Matos Romão, Fidelino Figueiredo, Goethe Institut. 
dirigir as suas preocupações. A isto se deve juntar ainda a preocupação na publicação de documentos relevantes que integrem esses arquivos.

O tratamento do livro antigo apresentava-se, e ainda se apresenta, como outra das prioridades. Em causa está o cumprimento de dois deveres: o de dar a conhecer um conjunto de valiosas obras, certamente importantes para investigações que estão a decorrer, ao mesmo tempo que se assegura a preservação e a segurança desse mesmo património. Por isto, dando continuidade ao trabalho de preservação e restauro do livro antigo, procedeu-se ao tratamento (conservação, digitalização e difusão) de obras do século XVI e XVII, esperando que este trabalho possa, em breve, vir a abranger as obras do século XVIII. A digitalização do livro antigo, processo oneroso que absorve recursos significativos, suscita questões de extrema importância, quer do ponto de vista da conservação, quer do ponto de vista da difusão, devendo por isso ser ponderada com o maior cuidado, pesando, caso a caso, vantagens e desvantagens, tendo também em conta o trabalho análogo já realizado por outras instituições similares, como, por exemplo, a Biblioteca Nacional.

Perante o que foi dito atrás, percebe-se que a Biblioteca da FLUL dispõe de um acervo rico e vasto, que conta com mais de 500.000 volumes (com obras impressas a partir do século XVI), entre os quais algumas importantes primeiras edições. A isto soma-se ainda nove incunábulos. A preservação a que me referi é, pois, uma evidência que se impõe de imediato. Entendo, porém, que o enriquecimento do património deve ser uma preocupação contínua que, de acordo com os recursos, infelizmente sempre escassos, não pode ser esquecida. Nesse sentido, e mau grado todas as restrições, a Biblioteca tem procurado, muitas vezes de acordo com as circunstanciais disponibilidades do mercado livreiro, adquirir obras relevantes, nomeadamente primeiras edições de consagrados autores portugueses. Importa sublinhar que, embora não se ponha em causa a importância das bibliotecas digitais, a importância histórico-cultural de todos os aspectos relacionados com a materialidade do objecto impresso impõe a continuidade da valorização do espólio bibliográfico em papel. 
Tocamos aqui o importante ponto da política de aquisições. A aquisição de obras antigas e de primeiras edições não pode comprometer a aquisição de obras recentes, quer genéricas, quer de especialidade, nomeadamente daquelas áreas estudadas na FLUL ${ }^{11}$. A existência de uma bibliografia actualizada, quer em revistas, quer em monografias, é decisiva para a qualidade do estudo e da investigação realizados na Faculdade. Por essa razão, parte muito significativa do orçamento da Biblioteca é distribuído pelos diversos departamentos de forma a que possam indicar a compra de revistas e de monografias mais oportunas e necessárias para a investigação e o estudo nas suas respectivas áreas científicas. O custo das obras ou a assinatura de revistas que possuem um interesse geral não são, naturalmente, imputadas aos departamentos, facto que, aliás, prova a necessidade de uma visão global na política de aquisições.

O elevado preço das revistas, que obriga a uma criteriosa escolha, é mais um argumento para a necessidade de a Biblioteca se abrir às novas tecnologias digitais, assegurando o acesso quer a monografias online, quer a bases de dados de publicações periódicas internacionais. Este último aspecto, que tem merecido uma maior atenção, constitui a única possibilidade, pelas razões expostas, de aceder a publicações periódicas cuja importância para o mundo académico não sofre qualquer contestação. Além das assinaturas feitas pela Reitoria para toda a Universidade de Lisboa (o caso da B-on), a FLUL tem ainda procurado parceiros nas outras unidades orgânicas da Universidade no sentido de promover assinaturas conjuntas de algumas bases de dados. Foi o caso, por exemplo da base Project Muse, assinada em parceria com o Instituto de Ciências Sociais, cuja utilidade é imensa, a avaliar pelo número de leitores que a consultam ${ }^{12}$. Por um conjunto de razões, onde se inclui este aspecto financeiro, é necessário não descurar estes novos recursos.

11 Convém não esquecer que, pela sua natureza, estas obras não integram as prioridades de aquisição das bibliotecas patrimoniais, como a Biblioteca Nacional ou as Bibliotecas Municipais.

12 A experiência tem mostrado que a conjugação das bases Project Muse e JStor proporcionou um acréscimo qualitativo da investigação. A possibilidade de consulta online, não apenas a estas, mas a outras bases, como por exemplo o Cambridge Companion to... revelou-se de extrema utilidade. 


\section{Organização Administrativa e Prestação de Serviços}

Acompanhando as alterações no plano da política científica, a Biblioteca, procedendo também a uma reorganização interna dos funcionários da Biblioteca - tarefa que depende fundamentalmente do Chefe de Divisão -, procurou melhorar os serviços prestados, (empréstimos, reservas de gabinetes, colaboração entre bibliotecas, apoio ao leitor...) tudo o que, em última análise, faz parte da rotina de uma biblioteca universitária. A este propósito, saliento apenas uma medida que muito beneficiou os utentes: o alargamento do horário de funcionamento da Biblioteca que, nos dias úteis está aberta das $9 \mathrm{~h}$ às $21 \mathrm{~h}$ e ao Sábado das $9 \mathrm{~h}$ às $19 \mathrm{~h}^{13}$. Embora este horário continue a ser "apertado" se confrontado com o que seria ideal, relativamente ao passado representa um enorme salto qualitativo, que a frequência de utilizadores, em número crescente, tem vindo claramente a justificar. E se é impensável que alunos, professores e investigadores de uma Faculdade de Letras não frequentem a sua biblioteca, é igualmente evidente que só uma biblioteca com um mínimo de condições, entre as quais se inclui o horário de funcionamento, pode, cumprindo a sua função e a sua vocação, atrair a comunidade académica. A par disto, o funcionamento coordenado e eficaz do pessoal afecto à Biblioteca, ainda que não seja imediatamente perceptível, é determinante para o bom funcionamento dos serviços ${ }^{14}$.

\section{Política Cultural}

Gostaria de dedicar uma última referência à política de difusão cultural. Embora com muitas iniciativas nesta área, em grande parte por mérito

13 Este é o horário entre Outubro e Junho. Durante os meses de Julho, Agosto e Setembro não temos ainda condições para manter este horário.

14 Relativamente aos funcionários da Biblioteca, procurou-se que a qualificação que possuem na área da biblioteconomia lhes permita uma projecção técnico-científica que corresponde, também, a uma projecção e a uma valorização dos serviços técnicos. Isso tem acontecido, por exemplo, mediante a participação de alguns funcionários da Biblioteca em projectos de investigação que alguns centros estão a desenvolver. 
dos que se ocupam destas questões, esta tem sido a vertente para a qual têm sido canalizados menos meios, em função das prioridades existentes. Ainda assim, é preocupação da Biblioteca abrir-se ao exterior, ultrapassar os limites estritos das paredes da Faculdade e chamar a si a comunidade de pessoas interessada nas letras, na arte, na ciência, na cultura. Neste âmbito, correspondendo também a pedidos que lhe são dirigidos, as exposições (nomeadamente dos espólios doados), as apresentações de livros, os debates, entre outras iniciativas, têm sido frequentes. No fundo são actividades que se integram e harmonizam com a vocação da Biblioteca.

Em traços sintéticos, estas são as ideias que têm orientado a política seguida pela Biblioteca da Faculdade de Letras da Universidade de Lisboa. Para o futuro, importa certamente desenvolver e aprofundar perspectivas já delineadas e dar mais atenção a aspectos até agora lateralizados, como por exemplo a área do arquivo. Estes, no entanto, foram os caminhos trilhados nos últimos anos; de acordo com a minha única intenção, logo expressa inicialmente, deles espero ter aqui deixado um retrato sugestivo. 
José Augusto Cardoso Bernardes é Professor da Faculdade de Letras da Universidade de Coimbra e Diretor da Biblioteca Geral da Universidade

Ana Maria Eva Miguéis é coordenadora do Serviço Integrado das Bibliotecas da Universidade de Coimbra

Carla Ferreira é bibliotecária nos Serviços de Biblioteca e Documentação da Faculdade de Letras da Universidade de Coimbra. 


\section{Série Documentos}

Imprensa da Universidade de Coimbra

Coimbra University Press

2015

C •

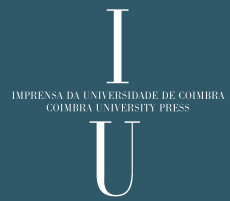

